\title{
Conservative surgery for mitral valve disease: clinical and echocardiographic analysis of results
}

\author{
OA ADEBO, JK ROSS
}

From the Wessex Cardiac and Thoracic Centre, Southampton General Hospital, Southampton.

ABSTRACT Eighty-five patients underwent mitral valve reconstruction by the Carpentier method from January 1976 to December 1981 . Concomitant procedures were performed in 30 patients (aortic valve replacement in 23, coronary revascularisation in six, and tricuspid valve repair in seven). Before operation 76 patients $(89 \%)$ were in clinical class II or III (New York Heart Association) and atrial fibrillation was present in 50. Thirty-six patients had valvular incompetence, while 26 had pure stenosis. The aetiology was rheumatic in 57 cases and dysplastic in 21 . The patients were assessed for clinical improvement, durability of valve repair, thromboembolism, and survival. There was one death, an operative mortality rate of $1 \cdot 2 \%$, and 63 of 74 patients followed for one to six years were in clinical class I after operation. The actuarial survival was $92 \%$ with a $93 \%$ incidence of freedom from thromboemboli at five years. Six patients had embolic episodes, four of whom had aortic valve replacement. Three patients had a repeat operation 16-20 months later, a valve failure rate of $6.7 \%$. Nineteen patients with ruptured chordae had postoperative echocardiographic assessment of myocardial and mitral valve functions; the peak rates of dimension changes of the left ventricular cavity (indicative of flow across the mitral valve) fell to normal in most patients, and the left ventricular end-diastolic dimensions decreased significantly from $6.4(1.53)$ to $5.09(1.31) \mathrm{cm}$ (mean and SD) $-\mathrm{p}<0.05$. Our results confirm that reconstructive mitral surgery is able to restore and maintain normal valve function in addition to providing satisfactory relief of symptoms.

In the past decade valve replacement has become the standard surgical treatment for serious mitral valve disease. ${ }^{1-4}$ Despite the improved opportunity for more precise commissurotomy afforded by technical developments, such as cardioplegic arrest, considerable numbers of stenotic valves are still replaced, ${ }^{5}$ though notable exceptions are reported. ${ }^{67}$ Historically, attempts to reconstruct regurgitant mitral valves with the use of extracorporeal circulation began in the late $1950 \mathrm{~s}$, preceding the development of an acceptable prosthetic valve and calling on many ingenious techniques. ${ }^{8-10}$ These early efforts were improved and developed by Carpentier ${ }^{11}$ and others ${ }^{12-14}$ with functional results similar to those achieved with valve replacement surgery, but the very success of valve replacement has tended to inhibit interest in conservative valve surgery. Difficulty with case selection, lack of pre-

Address for reprint requests: Sir Keith Ross, Wessex Cardiac and Thoracic Centre, Southampton General Hospital, Southampton SO9 4XY

Accepted 28 April 1983 dictability of results, and worries about possibly committing the patient to further surgery ${ }^{11415}$ have all contributed to a reluctance to embark on learning a new technique requiring a certain artistry that does not appeal to everyone. We have therefore reviewed our experience with conservative mitral valve surgery for both degenerative and rheumatic disease during a six-year period, with clinical and echocardiographic evaluation of our results.

\section{Patients and methods}

From January 1976 to December 1981 a total of 372 patients underwent surgery for mitral valve disease with cardiopulmonary bypass at the Wessex Cardiac Centre in Southampton. Of these, 85 (23\%) underwent reconstruction of their valve and comprise the study group. Excluded from this group were patients requiring only commissurotomies for correction of mitral stenosis. Attempted repair of regurgitant valves was the policy of only one of the cardiac surgeons in the unit during the study period.

The patients ranged in age from 16 to 71 years 

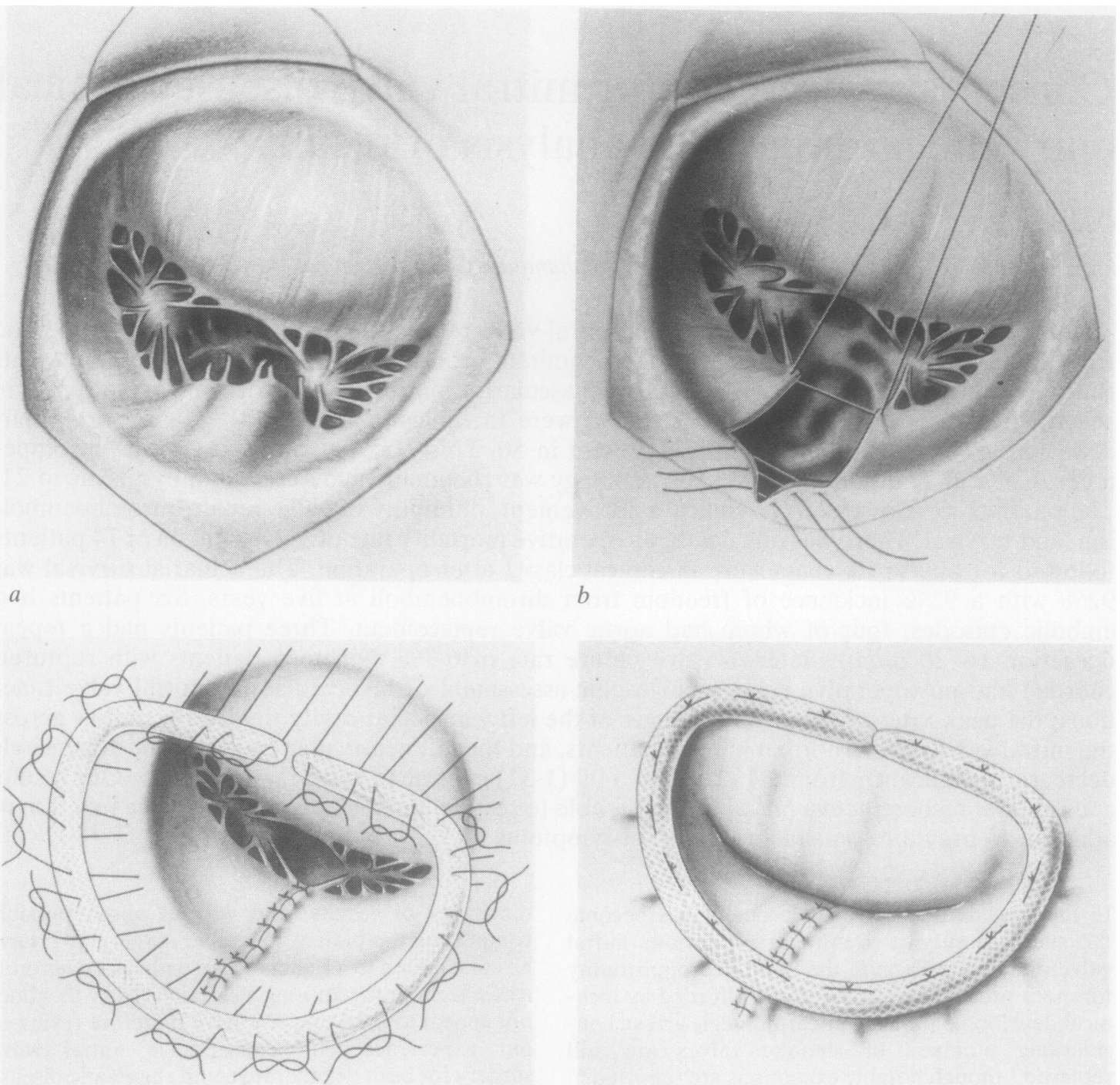

Fig 1 Operative technique for repair of ruptured chordae: (a) area of unsupported leaflet outlined; (b) resected and repaired; (c) implantation of mitral ring; (d) for annuloplasty and stabilisation of the valvuloplasty.

(mean 53.7 years), the male:female ratio being $1: 1 \cdot 6$. Seventy-six patients were in functional class II or III (classification of the New York Heart Association-NYHA). The causes were rheumatic disease in 57 cases, dysplastic (degenerative) disease in 21 , endocarditis in two, congenital abnormality in one, and undetermined in four. The functional impairment was pure incompetence in 36 , pure stenosis in 26 , and mixed in 23 . The dominant rhythm disturbance was atrial fibrillation, present in 50 patients. Preoperative cardiac catheterisation and angiography were performed in all patients, with echocardiography in a few.

The technique of valve reconstruction used was essentially that described by Carpentier et $a^{16-18}$ with division of fused commissures, thinning of thickened leaflets, mobilisation of fused chordae, resection of prolapsed leaflets, and remodelling of the mitral annulus on a prosthetic ring (fig 1). There were no chordal shortening procedures in the series. Moderate generalised hypothermia $\left(28-30^{\circ} \mathrm{C}\right)$ was used with continuous cross-clamping of the aorta 
during valve repair. Myocardial protection was provided with infusion of cold cardioplegic solution ( $\mathrm{St}$ Thomas's) into the aortic root or, in the presence of aortic regurgitation, into the coronary ostia. Intraoperative assessment of the mitral valve was achieved by the introduction of blood under pressure via an apical vent catheter with simultaneous venting of the aortic root. ${ }^{19}$ Thirty patients required surgery for another valve or coronary artery disease during the mitral procedure. Anticoagulants were given to patients with mitral rings for six to eight weeks, while for those with mechanical aortic valves they were continued indefinitely. There was an initial visit at six weeks after discharge, followed by annual reviews. Follow-up periods extended from one to six years (mean 3.5 years).

After operation, 19 of the 21 patients with dysplastic mitral valve incompetence (ruptured chordae tendinae) were assessed for myocardial and mitral valve function by real-time $\mathrm{M}$-mode echocardiography after a mean interval of 45 months. The results were digitised and computer analysed to provide values of the peak rate of dimension change of the left ventricular transverse dimension. ${ }^{20}$

Statistical analysis of results was performed with paired Student's $t$ tests.

\section{Results}

There was one hospital death, a mortality rate of $1.2 \%$, contrasting with an overall rate of $4.03 \%$ for all patients undergoing surgery for mitral valve disease during the same period. This single early death occurred in a patient having concomitant aortic valve replacement for subacute bacterial endocarditis and resulted from unheralded acute aortic dissection with rupture two weeks after surgery.

The reconstructive procedures performed on the mitral valves are outlined in table 1 . Annuloplasty with or without valvuloplasty was required in most cases. Concomitant procedures were performed in 30 patients, aortic valve replacement in 23 , tricuspid valve repair in seven, and coronary revascularisation in six.

The clinical results in 74 patients, followed for
Table 1 Reconstructive procedures on the mitral valve in 85 patients

\begin{tabular}{lr}
\hline Procedure & No \\
\hline Annuloplasty* $^{*}$ & 39 \\
Annuloplasty $^{*}$ and valvuloplasty & 40 \\
Leaflet resection $^{\dagger}$ & 25 \\
Leaflet grafting $^{\text {Leaflet mobilisation }}$ & 4 \\
\hline
\end{tabular}

* All with ring except in one patient.

†Including mobilisation of chordal apparatus.

one to six years, are shown in table 2. A satisfactory result occurred in all but two patients (one of whom recently sustained a myocardial infarct), with $85 \%$ in NYHA class I; eight patients are lost to followup. There were four late deaths $(5.4 \%)$, from six weeks to four years after operation. Two deaths resulted from left ventricular failure, one from ventricular arrhythmia, and one from progression of intraoperative neurological complications. Three patients required reoperation for failed valve repair

Table 2 Clinical results of the operation in 74 patients

\begin{tabular}{lll}
\hline NYHA class & No of patients \\
\cline { 2 - 3 } & Before operation & After operation* \\
\hline I & 0 & 63 \\
II & 21 & 9 \\
III & 48 & 2 \\
IV & 5 & 0 \\
\hline
\end{tabular}

*Mean follow-up 3.5 years.

NYHA-New York Heart Association.

(table 3). Dehiscense of the Carpentier ring occurred on only one occasion. Reoperation in the patient (No 1) with ruptured posterior chordae was advised for mitral stenosis, although excellent function of the repaired mitral valve had been shown at catheterisation and was confirmed during operation. The tricuspid valve had to be replaced and the mitral valve was also replaced after acute heart failure following bypass, but it is doubtful whether the repaired mitral valve was responsible for the difficult problem which arose and which remains largely unexplained.

Table 3 Reoperations after mitral reconstructions

\begin{tabular}{|c|c|c|c|c|c|}
\hline Patient & Age (y) & Aetiology & Cause of failure & Second operation & Interval $(m)$ \\
\hline 1 & 57 & Chordal rupture & $\begin{array}{l}\text { Mitral stenosis, } \\
\text { tricuspid requrgitation }\end{array}$ & $\begin{array}{l}\text { MVR } \\
\text { TVR }\end{array}$ & 16 \\
\hline 2 & 60 & $\begin{array}{l}\text { Chordal elongation and } \\
\text { annular dilatation }\end{array}$ & Dehiscence of ring & MVR & 20 \\
\hline 3 & 34 & Rheumatic disease & $\begin{array}{l}\text { Mitral stenosis and } \\
\text { subchordal fusion }\end{array}$ & MVR & 31 \\
\hline
\end{tabular}

*MVR-mitral valve replacement; TVR-tricuspid valve replacement. 
(a)

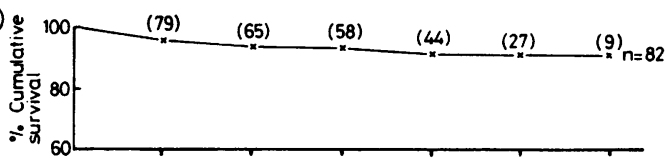

(b)

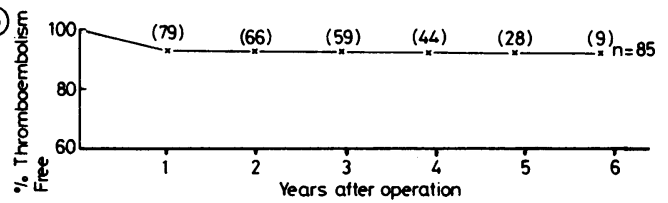

Fig 2 (a) Actuarial curve of survival (hospital mortality excluded); (b) actuarial curve of freedom from thromboembolism.

Six patients sustained thromboembolic complications, all within one year of surgery, without any permanent neurological impairment. Four of the six had had an associated aortic valve replacement (three with homografts); two of the four were in atrial fibrillation. Embolic episodes occurred in only two of the patients with isolated repair, both in atrial
Table 4 Summary of echocardiographic data (means and $S D)$ in patients with ruptured chordae

\begin{tabular}{llll}
\hline Subjects & No & $P R D C(\mathrm{~cm} / \mathrm{s})$ & $E F(\%)$ \\
\hline Patients & & & \\
Before repair & 10 & $20 \cdot 0(10 \cdot 8)$ & $65(17)$ \\
After repair & 18 & $9.0(2.5)$ & $53(18)$ \\
Normal controls & 15 & $11.8(4.5)$ & $65(11)$ \\
\hline
\end{tabular}

PRDC-peak rate of dimensional change of left ventricle; EFejection fraction.

fibrillation, within six weeks of surgery. The actuarial analysis of results ${ }^{21}$ (fig 2) produced curves with a $92 \%$ survival and a $93 \%$ incidence of freedom from emboli at five years.

Table 4 compares the echocardiographic results obtained before and after operation in patients with repaired ruptured chordae with normal controls. The peak rate of dimension change of the left ventricular cavity fell significantly in all cases (mean reduction $45 \%, p<0.01$ ); values within the stenotic range occurred in three patients, all of whom were in clinical class I. The left ventricular end-diastolic
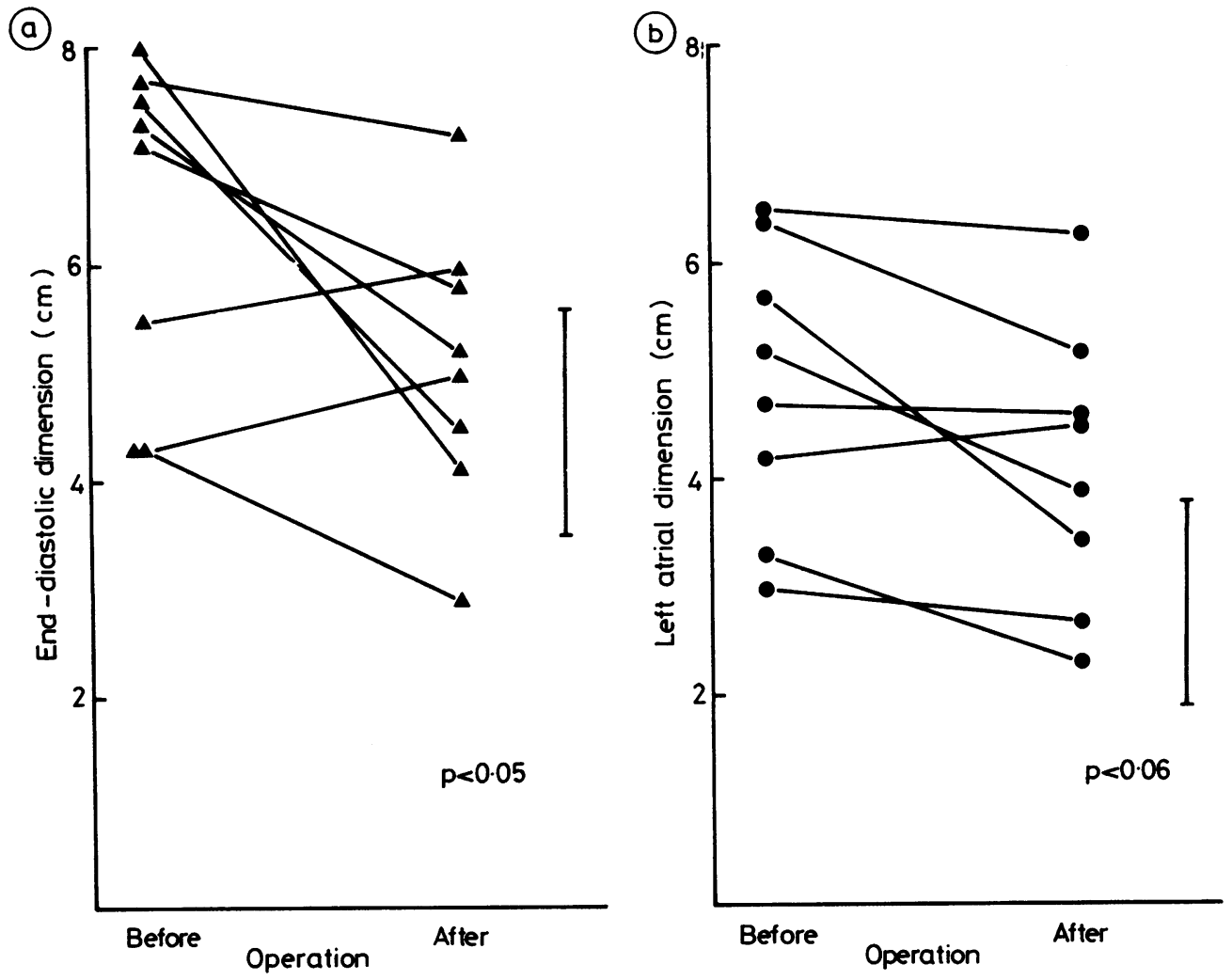

Fig 3 Echocardiographic changes in (a) end-diastolic dimensions $(p<0.05)$ and (b) left atrial dimensions $(p<0.06)$ for repaired ruptured chordae $(n=8)$. Vertical bar represents range of normal values. 


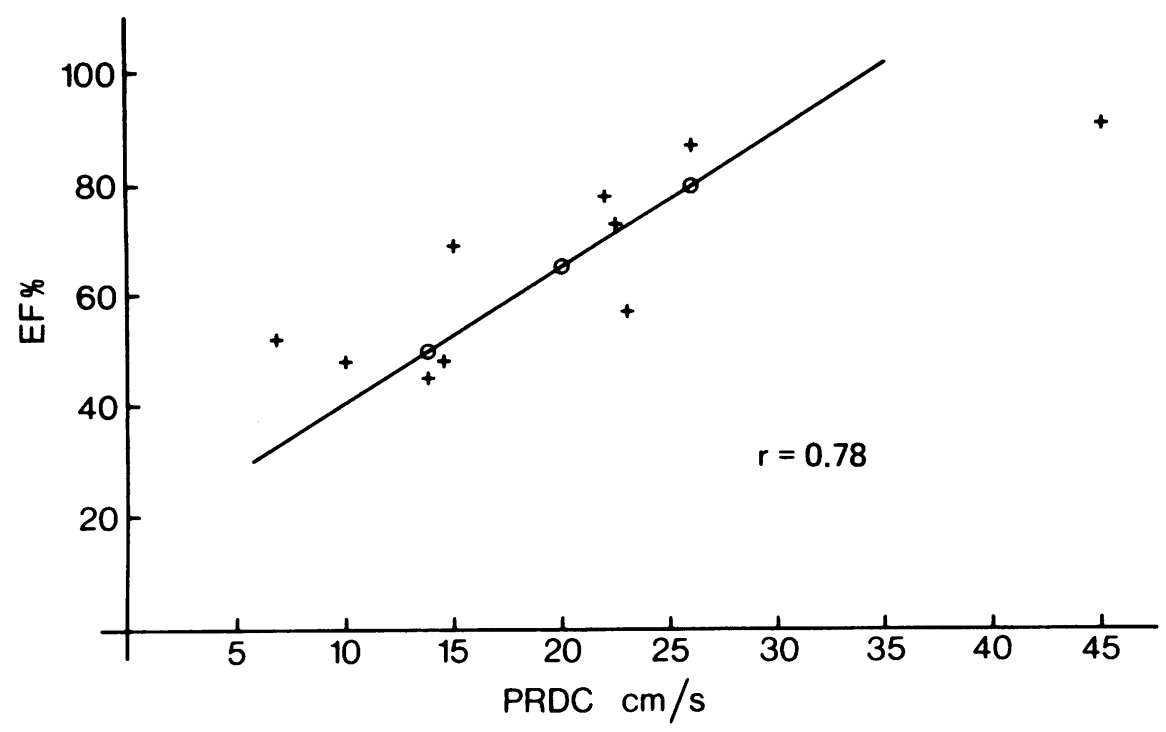

Fig 4 Relationship between ejection fractions (EF) and peak rates of dimension change $(P R D C)$ before operation in ruptured chordae $(n=10)(r=0.78)$.

dimension decreased significantly from $6.46(1.53)$ to $5.09(1.31)$ (mean and SD) $\mathrm{cm}(\mathrm{p}<0.05)$ (fig $3 a$ ), while the left atrial dimension (LAD) declined by a mean value of $12 \%$ (fig $3 b$ )-an alteration approaching statistical significance $(p<0.06)$. Other changes observed included a fall in diastolic closure rate in 19 patients, paradoxical septal motion in eight (of 18 cases), and posterior diastolic movement of the posterior mitral leaflet in 14 (of 15 cases). A significant coefficient of correlation $(r=$ 0.78 ) occurred between ejection fractions (EF) and PRDC in the preoperative determination (fig 4). This relationship was not found after operation or in normal controls.

\section{Discussion}

The range of techniques available for mitral valve reconstruction ${ }^{911-1422}$ indicates that none has yet achieved overwhelmingly superior results. Nevertheless, as noted by Oury and colleagues, ${ }^{15}$ the technique of Carpentier systematically applies corrective measures to deformities at each level of the mitral valve apparatus. Its efficacy has been demonstrated by angiocardiographic and echocardiographic studies $^{132324}$ and excellent long-term clinical results have been published. ${ }^{11}$

Our operative mortality rate $(1.2 \%)$ compares favourably with the $1.89 \%$ reported by Duran et al ${ }^{13}$ and the actuarial survival $(90 \%)$ and incidence of freedom from thromboemboli $(95 \%)$ after five years are comparable to those reported by Carpentier $e t$ al. " Similar results are reported with other techniques of mitral repair. ${ }^{1214}$ Comparable data for mitral valve replacement are an actuarial survival rate of $82-90 \%$ at five years for a bioprosthesis ${ }^{13}$ and of $66-78 \%$ for a mechanical prosthesis, ${ }^{24}$ with rates of $87-98 \%$ and $69-95 \%$ respectively for freedom from embolism. Despite the presence of a systolic murmur after operation in $25 \%$ of our cases, only three patients have required reoperation for failed repair. Carpentier found non-haemodynamically significant murmurs in $55 \%$ of patients followed for one to 10 years, ${ }^{11}$ while Duran and Ubago reported an early incidence of $44 \%$ using a totally flexible annular ring. ${ }^{24}$

Studies based on assessment of clinical results have confirmed that both mitral valve replacement and repair provide satisfactory symptomatic relief, with $84 \%^{1}$ and $80 \%^{15}$ of patients in NYHA class I respectively. A more critical comparison is afforded by relating the durability of valve repair to the prosthesis-related complications after mitral valve replacement. Our valve failure rate of $6.7 \%$, similar to the rate of Duran et $a^{13}$ and Carpentier," contrasts with a failure rate of $15 \%$ at 10 years with a bioprosthesis ${ }^{11}$ and a valve-related complication rate of $11.9 \%$ per patient-year with a mechanical prosthesis. ${ }^{4}$

The haemodynamic evaluation of valve surgery previously required angiocardiography,,$^{132324}$ which limited its availability. With the establishment of its 
reliability and reproducibility in the estimation of left ventricular size, ${ }^{2526}$ echocardiography now provides non-invasive determinations of ventricular function, readily repeatable in the postoperative period. It also affords a more detailed study of ventricular filling patterns ${ }^{27}$ and of mitral valve leaflet motion. ${ }^{28-30}$

Echocardiography showed posterior diastolic movement of the posterior leaflet in $93 \%$ of patients with repaired ruptured chordae, confirming restoration of normal mitral leaflet motion. ${ }^{2930}$ The reduction in diastolic closure rate noted in seven of 14 patients has been shown to be unrelated to valve orifice dimension. ${ }^{28}$ Paradoxical septal motion, noted in eight patients, has been described previously after valve replacement and is usually reversible. ${ }^{3132}$ The abnormal left ventricular filling pattern resulting from this is attributed to the presence of a rigid mitral valve ring. ${ }^{27}$ Nevertheless, the observation of a normal peak rate of dimension change of the left ventricular cavity (indicative of a normal filling rate) after operation in all but three patients confirms the experience of others with valve repair ${ }^{1427}$ and contrasts with the findings after valve replacement. ${ }^{27}$ The normal ventricular filling rate reflects the presence of a normal rate of blood flow across the mitral valve orifice. ${ }^{142027}$ The observed reduction in left arterial dimension in our patients agrees with the report of Sherrid et al, ${ }^{33}$ though we were unable to correlate it with the level of clinical improvement. The decreased ejection fractions after repair accord with the results of previous echocardiographic ${ }^{3132}$ and haemodynamic studies, ${ }^{23}$ but echocardiographic determinations of ejection phase indices are considered unreliable after cardiac surgery, owing to abnormality of septal motion. ${ }^{34}$ In such circumstances the end-diastolic dimension of the left ventricle provides the most reliable index of ventricular function; reductions in the end-diastolic dimension have been found uniformly to correlate with the level of clinical improvement after successful valve surgery. ${ }^{31}{ }^{32}$ There were significant reductions in all our patients in clinical class I and II after surgery $(p<0.05)$. The observed correlation between peak rate of dimension change of the left ventricular cavity and ejection fractions before operation suggests that in these patients myocardial contractility was predominantly determined by the abnormal preload before correction of mitral reflux. Once valve function had been restored the correlation was lost.

We have confirmed that an acceptable functional improvement is obtained with Carpentier's technique of mitral valvuloplasty. The method is applicable regardless of aetiology, with a valve failure rate of less than $7 \%$ after 3.5 years of follow-up.
Echocardiographic evaluation in a series of patients undergoing repair for ruptured posterior chordae shows that leaflet motion and ventricular filling become normal; improvement in myocardial function occurs in association with observed clinical benefit. The maintenance of normal mitral valve leaflet motion after valvuloplasty for ruptured chordae, as shown by echocardiography, indicates continuing normal function of both the repaired leaflet and the rest of the subvalve mechanism. This important observation is complementary to the results of studies of the ultrastructure of ruptured and unruptured chordae, ${ }^{35}$ which have shown that the unruptured chordae had no sign of degenerative change and could safely be preserved.

We wish to thank Drs A Johnson and N Conway, whose patients are reported; Dr B Keeton for his assistance with the echocardiographic studies; and Miss J Yard for her typing. Our gratitude also goes to Mrs Anne Longhurst for collection of the clinical material, Dr MJ Campbell for the statistical analysis; the department of teaching media for the illustrations; and Mrs Chris Chase, Miss Linda Whittle, and Mrs Molly Dack for their technical assistance.

\section{References}

' Ionescu MI, Smith DR, Hanson SS, et al. Clinical durability of the pericardial xenograft valve; ten years' experience with mitral replacement. Ann Thorac Surg 1982;34:265-77.

${ }^{2}$ Bjork VO, Henze A. Ten years' experience with the Björk-Shiley tilting disc valve. $J$ Thorac Cardiovasc Surg 1979;78:331-42.

${ }^{3}$ Borkon AM, McIntosh CL, Von Ruedin TJ, Morrow AG. Mitral valve replacement with the Hancock bioprosthesis: five to ten-year follow-up. Ann Thorac Surg 1981;32:127-37.

4 Tepley JF, Grunkemeier GL, Sutherland DH, et al. The ultimate prognosis after valve replacement; an assessment at twenty years. Ann Thorac Surg 1981;32:111-9.

${ }^{5}$ Laschinger JC, Cunningham JN, Baumann FG, et al. Early open radical commissurotomy. Surgical treatment of choice for mitral stenosis. Ann Thorac Surg 1982;34:287-98.

${ }^{6}$ Halseth WL, Elliott DP, Walker EL, et al. Open mitral commissurotomy. A modern re-evaluation. J Thorac Cardiovasc Surg 1980;80:842-8.

${ }^{7}$ Ullyot DJ. Discussion in Laschinger JC, Cunningham JN, Baumann FG, et al. Early open radical commissurotomy: surgical treatment of choice for mitral stenosis. Ann Thorac Surg 1982;34:287-98.

${ }^{8}$ Lillehei CW, Gott VL, De Wall RA, Varco RL. The surgical treatment of stenotic or regurgitant lesions of the mitral and aortic valves by direct vision utilising a pump-oxygenator. J Thorac Surg 1958;35:154-91. 
9 Wooler GH, Nixon PGF, Grimshaw VA, et al. Experiences with the repair of the mitral valve in mitral incompetence. Thorax 1962;17:49-57.

${ }^{10}$ Gerbode F, Kerth WJ, Osborn JJ, Selzer A. Correction of mitral insufficiency by open operation. Ann Surg 1962;152:847-54.

"Carpentier A, Chauvaud S, Fabiani JN, et al. Reconstructive surgery of mitral valve incompetence. $J$ Thorac Cardiovasc Surg 1980;79:338-48.

${ }^{12}$ Reed GE, Pooley RW, Moggio RA. Durability of measured mitral annuloplasty. J Thorac Cardiovasc Surg 1980;79:321-5.

${ }^{13}$ Duran GG, Pomar JL, Revuelta JM, et al. Conservative operation for mitral insufficiency. Critical analysis supported by post-operative haemodynaic studies of 72 patients. J Thorac Cardiovasc Surg 1980;79:32637.

${ }^{14}$ Shore DF, Wong P, Paneth M. Results of mitral valvuloplasty with a suture plication technique.J Thorac Cardiovasc Surg 1980;79:349-57.

${ }^{15}$ Oury JH, Peterson KL, Folkerth TL, Daily PO. Mitral valve replacement versus reconstruction: an analysis of indications and results of mitral valve procedures in a consecutive series of 80 patients. J Thorac Cardiovasc Surg 1977;73:825-35.

${ }^{16}$ Carpentier A, Deloche A, Dauptain J, et al. A new reconstructive operation for correction of mitral valve and tricuspid insufficiency. J Thorac Cardiovasc Surg 1971;61:1-13.

${ }^{17}$ Carpentier A. Plastic and reconstructive mitral valve surgery. In: Kalmanson D, ed. The mitral valve. $A$ pluridisciplinary approach. Acton, Mass: Publishing Sciences Group Inc, 1976:527-40.

${ }^{18}$ Carpentier A, Relland J. Deloche A, et al. Conservative management of the prolapse mitral valve. Ann Thorac Surg. 1978;26:294-302.

${ }^{19}$ Nair KK, Yates AK. Direct evaluation of mitral valve function during surgery following conservative procedures. J Thorac Cardiovasc Surg 1977;73:684-5.

${ }^{20}$ Gibson DG, Brown D. Measurement of instantaneous left ventricular dimension and filling rate in man, using echocardiography. Br Heart J 1973;35:1141-9.

${ }^{21}$ Hill AB. Principles of medical statistics. 7th ed. London: The Lancet Ltd, 1971:220-36.

${ }^{22} \mathrm{McGoon} \mathrm{D}$. Repair of mitral insufficiency due to rup- tured chordae tendinae. J Tharac Cardiovasc Surg 1959;39:357-62.

${ }^{23}$ Lessana A, Herreman F, Cosma H, et al. Haemodynamic and cineangiographic study before and after mitral valvuloplasty (Carpentier's technique). Circulation $1981 ; 64$,suppl 2:195-202.

${ }^{24}$ Duran CG, Ubago JLM. Clinical and haemodynamic performance of a totally flexible prosthetic ring for atrio-ventricular valve reconstruction. Ann Thorac Surg 1976;22:458-63.

${ }^{25}$ Pombo JF, Troy BD, Russell RO. Left ventricular volumes and ejection fraction by echocardiography. Circulation 1971;43:480-90.

${ }^{26}$ Gibson DG. Estimation of left ventricular size by echocardiography. Br Heart J 1973;35:128-34.

${ }^{27}$ Sutton MG, Traill TA, Ghafoux AS, et al. Echocardiographic assessment of left ventricular lining after mitral valve surgery. Br Heart J 1977;39:1283-91.

${ }^{28}$ Mary DAS, Pakrashi BC, Wooler GH, Ionescu MI. Study with reflected ultrasound of patients with mitral valve repair. Br Heart J 1973;35:480-7.

${ }^{29}$ Shiu MF, Jenkins BS, Webb-Peploe MM. Echocardiographic analysis of posterior mitral leaflet movement in mitral stenosis. Br Heart $J$ 1978;40:3 $/ 2-6$.

${ }^{30}$ Thomas RD, Mary DAS, Ionescu MI. Echocardiographic pattern of posterior mitral valve leaflet movement after mitral repair. $B r$ Heart $J$ 1979;41:399-404.

${ }^{31}$ Burggraf GW, Craige E. Echocardiographic studies of left ventricular wall motion and dimension after valvular heart surgery. Am J Cardiol 1975;35:473-80.

${ }^{32}$ Schuler G, Peterson KL, Johnson A. Temporal response of left ventricular performance to mitral valve surgery. Circulation 1979;59:1218-31.

${ }^{33}$ Sherrid MV, Clark RD, Cohn K. Echocardiographic analysis of left atrial size before and after operation in mitral valve disease. Am J Cardiol 1979;43:171-8.

${ }^{34}$ Clark RD, Korcuska K, Cohn K. Serial echocardiographic evaluation of left ventricular function in valvular disease, including reproducibility guidelines for serial studies. Circulation 1980;62:564-75.

${ }^{35}$ Scott-Jupp W, Barnett NL, Gallagher PJ, Monro JL, Ross JK. Ultrastructural changes in spontaneous rupture of mitral chordae tendinae. J Pathol 1981;133:185-201. 